\author{
Agustin Oterino \\ Jesus Castillo \\ Julio Pascual \\ Amalia Cayon \\ Ana Alonso \\ Carlos Ruiz-Alegria \\ Natalia Valle \\ Fernando Monton \\ Nuria Ruiz-Lavilla
}

\title{
Genetic association study and meta-analysis of the HTR2C Cys23Ser polymorphism and migraine
}

Received: 20 May 2007

Accepted in revised form: 18 July 2007

Published online: 24 September 2007
Abstract The objectives of this study were to determine if the HTR2C Cys23Ser polymorphism is associated with migraine in a casecontrol study, and to perform a meta-analysis with present and previous available studies. The $H T R 2 C$ gene is located at the Xq24-q28 chromosomal band. This band was linked to migraine with aura (MA) in two Australian families. Using the HTR2C Cys23Ser allelic variant, this gene has been ruled out as a migraine gene in 3 out of 4 studies. Only the Japanese study reported a higher risk for MA $(\mathrm{OR}=6.11 ; 95 \%$ $\mathrm{CI}=1.70-21.97, p$ trend $<0.01)$. We performed a case-control study with 335 migraine subjects and 335 sex- and age-matched controls, and a meta-analysis pooling the results of the available data from MA subsets of patients. In the association study we found no significant differences among migraine and MA patients for this polymorphism. In the meta-analysis, under the fixed-effect model, the Ser allele did not confer higher risk for suffering MA (pooled $\mathrm{OR}=1.1 ; 99 \% \mathrm{CI}=0.8-1.5$, $p=0.499)$. Our study did not confirm the HTR2C Cys23Ser polymorphism as a risk factor for migraine and MA.
Keywords $H T R 2 C$ gene $\bullet$ Migraine - Migraine with aura $\bullet$ Case-control study $\bullet$ Meta-analysis 


\section{Introduction}

The serotonergic system has a pivotal role in migraine pathophysiology and therapy [1]. Triptans act through their coupling to some subtypes of serotonergic receptors. Significant allele sharing was found in the telomeric region of the $\mathrm{X}$ chromosome (Xq24-q28) in a linkage study with two Australian migraine families [2]. This chromosomal band contains, among others, the gene $H T R 2 C$ that codes for the $H T R 2 C$ receptor [3]. The HTR2C Cys23Ser allelic variant was shown to influence the metabolism of norepinephrine in the cerebrospinal fluid in a Finnish sample of predominantly alcoholic offenders [4], but this effect was not corroborated in any other study [5]. After this promising scenario with the $H T R 2 C$ gene, this gene was further discarded as a candidate in Australians using 2 single nucleotide polymorphisms (SNP) corresponding to Cys23Ser substitution, and a 3' untranslated region (UTR) SNP [6]. They found identical allelic frequencies for both SNPs in the total sample and specifically in the male subsample. The HTR2C Cys23Ser has also been analysed in 3 other populations with discrepant results [7-9]. In the Japanese study, a 6-fold higher risk for suffering from migraine with aura (MA) was found for subjects carrying at least one $H T R 2 C 23$ Ser allele, but the other 2 studies failed to demonstrate any such association.

Here we tested if the HTR2C Cys23Ser polymorphism modifies the risk for suffering from migraine, especially MA, in a matched case-control study, and also we performed a metaanalysis with present and previous available studies.

\section{Patients and methods}

\section{Subjects}

We recruited a sex- and age-matched sample of subjects consisting of 335 unrelated patients (aged 38.6 \pm 15.0 years) and 335 controls (aged $38.9 \pm 13.9$ years) (Table 1 ). The migraine patients were diagnosed as having IHS [10] migraine without aura (MO) (151; aged 41.9 \pm 16.5 years) and MA (184 cases; aged 35.7 \pm 13.0 years). Some 85 MA patients had also experienced MO attacks. All were Caucasians living in Cantabria, in northern Spain. Patients were recruited in our general neurological clinic, and the matched controls were mainly from among patients' friends. All cases and healthy controls were interviewed by an experienced neurologist. Informed consent was obtained from all patients and controls before entering the study. The protocol had been approved by our local ethics committee.

Genetic analysis

We performed allelic discrimination to detect the Cys23Ser poly- morphism using fluorogenic 3'-minor groove binding probes (MGB) in a real-time polymerase chain reaction (PCR) assay [11]. The PCR was performed in an ABI Prism 7000 thermocycle, using fluorescently labelled probes and primers following the manufacturer's instructions (Applied Biosystems). The reaction was carried out in a final volume of $5 \mathrm{ul}$ containing $1 \times$ Taqman Universal PCR Master Mix (Applied Biosystems). PCR cycling conditions consisted of one cycle of $2 \mathrm{~min}$ at $50 \mathrm{rC}$ and one of $10 \mathrm{~min}$ at $95^{\circ} \mathrm{C}$, followed by 48 cycles at $92^{\circ} \mathrm{C}$ for $15 \mathrm{~s}$ and $62^{\circ} \mathrm{C}$ for $1 \mathrm{~min}$. Genotyping was performed twice for each individual. The person who performed genetic analysis was blinded with respect to clinical status.

Statistics

Genotypic and allelic frequencies were cross-tabulated with regard to clinical group and sex. As we tested only X-linked markers, the Hardy-Weinberg equilibrium was analysed only in females. Odds ratios (ORs) were estimated using a logistic regression model to assess whether HTR2C Cys23Ser significantly contributed to predicting migraine, MA and MO. We constructed a logistic regression equation entering the polymorphism as a binary condition under a dominant model. For general significance, the $p$ value level was set at 0.01 . For categorical analyses, we report overall $\chi^{2}$ test of association $(\alpha=0.01)$. Further adjustments for multiple testing were applied (stratification for sex and type of migraine) using Bonferroni's method. The power of the association population was based on the alternative hypothesis of an associated rare allele at $\alpha=0.01$ exhibiting a prevalence of $15 \%$ in the general population. Therefore, in order to detect a two-fold increase in the case group we estimated the power of this study as greater than $80 \%$.

For meta-analysis, point estimates of ORs were calculated by the Mantel-Haensel method to investigate if the presence of the Ser allele increased the risk for MA vs. controls. Genotypes Cys/Ser and Ser/Ser were then grouped and named Ser+. The subgroup of patients identified as MA+MO was treated as MA patients. A fixed-effect model was initially applied to calculate a pooled OR estimate after Mantel-Haensel weighting, allowing for within-study variability. Cochran's $Q, H$ and $I^{2}$ statistical measures of consistency and heterogeneity were also calculated (see program MIX v.1.54 documentation [12]).

\section{Results}

Association study (Table 1)

A total of 244 women (135 MA) and 91 men (49 MA) with migraine, and 335 sex- and age-matched controls were genotyped for the HTR2C Cys23Ser polymorphism. The allele frequencies in controls were within the range of $0.81-0.91$ for Cys 
and $0.09-0.19$ for Ser reported in different ethnic populations $[3,13]$. The Hardy-Weinberg equilibrium fitted in MA females $(p=0.17)$ and in control females $(p=0.23)$. There were no significant genotypic differences among migraine females $\left(\chi^{2}=5.007 ; 4 \mathrm{df}, p=0.287\right)$ or males $\left(\chi^{2}=0.284 ; 2 \mathrm{df}, p=0.868\right)$ vs. controls. Some differences emerged after stratification by sex. A non-significant excess of the Ser allele was observed ( $p=0.031, \mathrm{~ns})$ for MA women vs. controls. Ser allele conferred a mildly higher risk for MA among females $(\mathrm{OR}=1.56 ; 99 \%$ CI: $0.8-2.9 ; p=0.060)$. Migraine males had lower $(0.132)$, but not significantly lower, rates of the Ser allele than females (0.166). As we did not match the sample among migraine cases by age, we introduced this variable in the comparisons between $\mathrm{MO}$ and MA. We did not observe significant differences in the effect of HTR2C genotypes between MO and MA in females or in males.

Meta-analysis (see Fig. 1)

We found four association studies and two linkage studies.
The clinical and genetic data from the Australian study [6] were obtained by personal communication with the authors and have been published elsewhere [14]. Briefly, they found 24 Ser+ MA patients (19 females) and 66 controls (55 females), and 96 MA patients (59 females) and 201 controls (144 females) lacking the Ser allele. Only the Japanese study [9] reported positive results. They observed a more than 6-fold increased risk for suffering from MA conferred by the Ser allele. They obtained a broad confidence interval, as their number of MA patients was very low. The present study, like the Australian, Danish [7] and Italian studies before [8], disclosed negative results (see Fig. 1 for details). The Japanese and Italian studies had a very low number of MA patients and one of them also of controls. The Ser allele was found in 109 out of 452 pooled MA cases, and in 180 out of 1055 pooled controls. Under the fixed-effect model (Table 2 and Fig. 1), the pooled OR reached $1.10(99 \%$ $\mathrm{CI}=0.76-1.58 ; p=0.498)$. Statistics $Q \quad(p=0.115)$, and $H=1.36(99 \% \mathrm{CI}=1.0-2.635)$ indicated neither significant heterogeneity within studies nor across-study variability $\left(I^{2}=46.14 \% ; 99 \% \mathrm{CI}=0-85.8 \%\right)$.

Table 1 Case-control study with HTR2C Cys23Ser polymorphism in the Cantabrian population: genotypic and allelic distribution

\begin{tabular}{|c|c|c|c|c|c|}
\hline \multirow[t]{2}{*}{ Women (n) } & \multicolumn{2}{|c|}{ Genotype (\%) } & \multirow[b]{2}{*}{ Ser/Ser } & \multicolumn{2}{|c|}{ Allele (\%) } \\
\hline & Cys/Cys & Cys/Ser & & Cys & Ser \\
\hline MA (135) & $92(68.1)$ & $36(26.7)$ & $7(5.2)$ & $220(81.5)$ & $50(18.5)$ \\
\hline MO (109) & $83(76.1)$ & $21(19.3)$ & $5(4.6)$ & $187(85.8)$ & $31(14.2)$ \\
\hline Controls (244) & $188(77.0)$ & $50(20.5)$ & $6(2.5)$ & $426(87.3)$ & $62(12.7)$ \\
\hline \multicolumn{6}{|l|}{ Males } \\
\hline MA (49) & & & & $42(85.7)$ & $7(14.3)$ \\
\hline MO (42) & & & & $37(88.1)$ & $5(11.9)$ \\
\hline Controls (91) & & & & 77 (84.6) & $14(15.5)$ \\
\hline
\end{tabular}

$\chi^{2}=5.007(4 \mathrm{df}), p=0.287$ for genotypic distribution in females

$\chi^{2}=0.284(2 \mathrm{df}), p=0.868$ for genotypic distribution in males

$\chi^{2}=4.740(2 \mathrm{df}), p=0.09$ for allelic distribution for females

Table 2 Summary results from the meta-analysis under the fixed-effect model

\begin{tabular}{|c|c|c|c|c|c|}
\hline \multirow[t]{2}{*}{ Study } & \multirow[t]{2}{*}{ Year } & \multicolumn{2}{|c|}{ Ser+l- } & \multirow[t]{2}{*}{ Weight $(\%)$} & \multirow[t]{2}{*}{ Association measure with $99 \% \mathrm{CI}$} \\
\hline & & Cases & Controls & & \\
\hline Griffiths et al. & 2000 & $24 / 96$ & $66 / 201$ & $18.68 \%$ & $0.68(0.3-1.4)$ \\
\hline Kusumi et al. & 2004 & $4 / 37$ & $7 / 360$ & $1.22 \%$ & $6.11(1.4-32.8)$ \\
\hline Burnet et al. & 1997 & $21 / 91$ & $28 / 129$ & $18.68 \%$ & $1.08(0.5-2.5)$ \\
\hline Racchi et al. & 2004 & $10 / 44$ & $9 / 30$ & $8.67 \%$ & $0.69(0.2-2.7)$ \\
\hline Present study & & $50 / 184$ & $70 / 335$ & $37.89 \%$ & $1.41(0.8-2.4)$ \\
\hline Meta-analysis & & $109 / 452$ & $180 / 1055$ & $100 \%$ & $1.1(0.8-1.6)$ \\
\hline
\end{tabular}




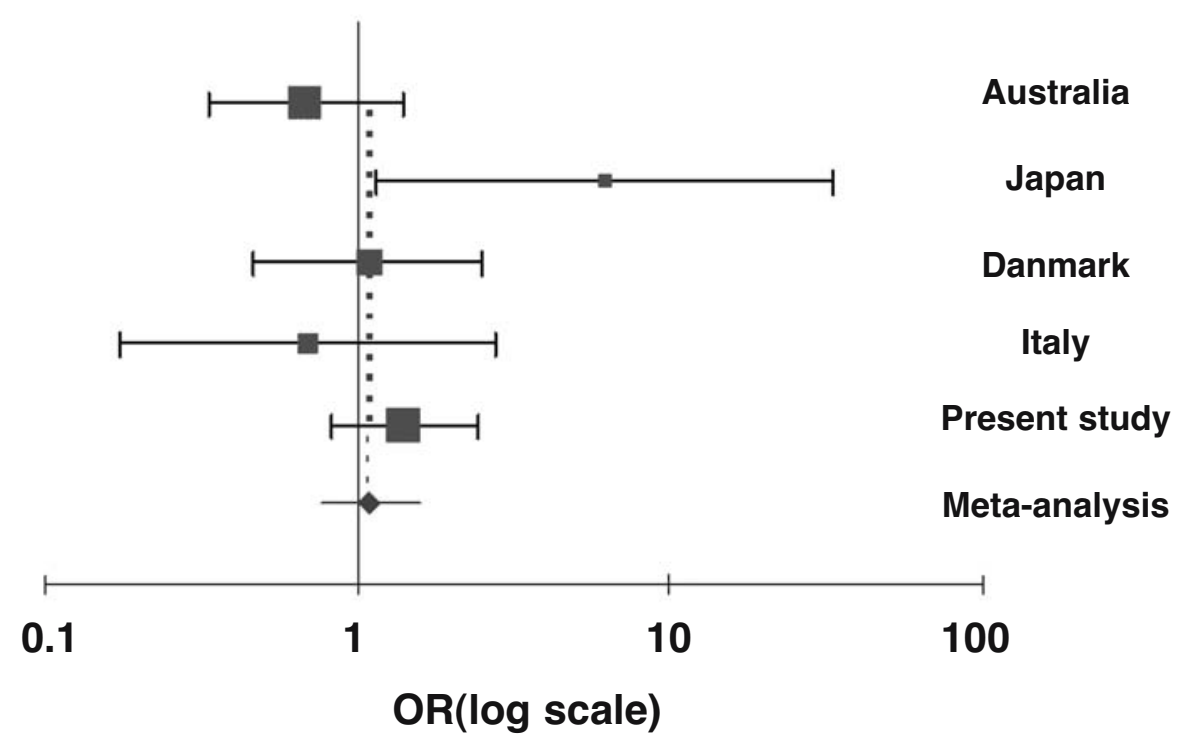

Fig. 1 Graphic representation of meta-analysis data under the fixed-effect model. Bars represent the $99 \% \mathrm{CI}$ and boxes indicate the respective OR. The size of boxes is proportional to the weight in the pooled results. ORs were logarithmically scaled

\section{Discussion}

In our association study we failed to detect genetic association of HTR2C Cys23Ser polymorphism with migraine. Even when we observed an excess of Ser allele, which conferred a mildly higher risk for suffering from MA in females (OR=1.56; 99\% CI: $0.8-2.9 ; p=0.060$ ), this effect was not significant. A loss of power is evident after sex stratification. The meta-analysis also failed to demonstrate the genetic association of MA with HTR2C Cys23Ser polymorphism. The Danish study found similar results to ours. The Australian study even showed a lower frequency of Ser allele in MA cases than in controls. The only positive study was performed in Japan. In this ethnic group, the Ser allele frequency was very low in controls and in MO patients. The participants in the Danish study were mainly men $(n=137)$ and there was a very low number of female controls $(n=34)$. Our study was matched for sex and age as the Australian one, and we found a higher prevalence of Ser allele in women than in men. The meta-analysis therefore included five studies with important clinical, ethnic and numerical differences that might bias the final result. Taking into account these limitations, the power of our meta-analysis was low, hence we could only exclude OR $>1.8$. Other serotonin receptors have been genetically studied in migraine with mainly negative results $[8,15-17]$.

In conclusion, although the HTR2C Cys23Ser is an attractive variant of a gene functionally implicated in migraine, we could not demonstrate that this polymorphism is associated with either migraine or MA. The differences observed across the studies may also be explained by their limited power due to small sample sizes, mainly the low number of MA females, selection bias and ethnic differences. Our meta-analysis showed no significant involvement of the Ser allele, and it is not likely that this polymorphism is involved in MA.

Acknowledgement This work was funded by API/22/05 of the "Fundación Marqués de Valdecilla-IFIMAV", Pfizer Fdn and FISS Project (PI05388) of the Instituto Carlos III.

\section{References}

1. Ferrari MD, Saxena PR (1993) On serotonin and migraine: a clinical and pharmacological review. Cephalalgia 13:151-165
2. Nyholt DR, Curtain RP, Griffiths LR (2000) Familial typical migraine: significant linkage and localization of a gene to Xq24-28. Hum Genet 107:18-23
3. Lappalainen J, Zhang L, Dean M et al (1995) Identification, expression, and pharmacology of a Cys23-Ser23 substitution in the human $5 \mathrm{HT} 2 \mathrm{C}$ receptor gene (HTR2C). Genomics 27:274-279 
4. Lappalainen J, Long JC, Virkkunen M et al (1999) HTR2C Cys23Ser polymorphism in relation to CSF monoamine metabolite concentrations and DSM-III-R psychiatric diagnoses. Biol Psychiatry 46:821-826

5. Jonsson EG, Bah J, Melke J et al (2004) Monoamine related functional gene variants and relationships to monoamine metabolite concentrations in CSF of healthy volunteers. BMC Psychiatry 4:4

6. Johnson MP, Lea RA, Curtain RP et al (2003) An investigation of the 5-HT2C receptor gene as a migraine candidate gene. Am J Med Genet Part B (Neuropsychiatric Genet) 2003; 117B:86-89

7. Burnet PW, Harrison PJ, Goodwin GM et al (1997) Allelic variation in the serotonin 5HT2C receptor gene and migraine. Neurorepor 8:2651-3
8. Racchi M, Leone M, Porrello E et al (2004) Familial migraine with aura: association study with 5-ht1B/1D, 5HT2C, and hSERT polymorphisms. Headache 44:311-317

9. Kusumi M, Araki H, Ijiri T et al (2004) Serotonin $2 \mathrm{C}$ receptor gene Cys23Ser polymorphism: a candidate genetic risk factor of migraine with aura in Japanese population. Acta Neurol Scand 109:407-409

10. The International Classification of Headache Disorders, $2^{\text {nd }}$ ed. Cephalalgia 2004;24 [suppl 1]:1-151

11. Kutyavin IV, Afonina IA, Mills A et al (2000) 3'-minor groove binder-DNA probes increase sequence specificity at PCR extension temperatures. Nucleic Acids Res 28:655-661

12. Bax L, Yu LM, Ikeda N et al (2006) MIX: Comprehensive Free Software for Meta-analysis of Causal Research Data-Version 1.54. 2006. Internet address: http://www.mix-for-metaanalysis.info/documentation.html.
13. Gutierrez B, Fananas L, Arranz MJ et al (1996) Allelic association analysis of the 5-HT2C receptor gene in bipolar affective disorder. Neurosci Lett 212:65-7

14. Mathew J. Doctoral Thesis. Griffith University, 2005.

15. Yang XS, Xu XP, Yang QD (2006) No association of C-1019G promoter polymorphism of 5-HT1A receptor gene with migraine. Eur J Neurol 13:533-5

16. Juhasz G, Zsombok T, Laszik A et al (2003) Association analysis of 5HTTLPR variants, 5-HT2a receptor gene $102 \mathrm{~T} / \mathrm{C}$ polymorphism and migraine. J Neurogenet 17:231-40

17. Erdal ME, Herken H, Yilmaz M, Bayazit YA (2001) Association of the T102C polymorphism of 5-HT2A receptor gene with aura in migraine. J Neurol Sci 188:99-101 